\title{
Feature-based Integration of Product, Process and Resources
}

\author{
S. HAASIS ${ }^{1}$, D. FRANK ${ }^{1}$, B. ROMMEL ${ }^{1}$ and M. WEYRICH ${ }^{2}$ \\ ${ }^{1}$ DaimlerChrysler AG - Ulm, R\&T, Germany \\ ${ }^{2}$ DaimlerChrysler AG - Stuttgart, IT, Germany
}

\begin{abstract}
The processes currently deployed within the organization of today are being greatly impacted by the demand for drastic reductions in lead-times accompanied by cuts in development and manufacturing costs. Furthermore, the trend towards geographic separation of development and manufacturing facilities and the growing requirement that external partners be seamlessly integrated into internal processes, together with increasing globalisation in manufacturing which necessitates that product design take - often very different - manufacturing conditions into consideration, make the efficient design of both internal and cross-organizational process chains, i.e. comprehensive, complete digital product and production planning, a necessity. The use of features as carriers of descriptive and semantic information within the product development process has led to a substantial decrease in redundant data input and, thus, to a significant reduction in effort and the probability of errors occurring while, at the same time, supporting a product design which is aligned with the manufacturing processes deployed. Supplemented by process data and methods geared for the specification of production aspects and workflows, feature-based process models enhance the transparency of manufacturing capability and resource modelling, thus serving as the foundation for the introduction of new organizational concepts such as simultaneous or concurrent engineering. This work describes the role features play in an organization's overall process chain: the connection between design, manufacturing and measuring features and their consolidation to a backbone for the continuous flow of information for the complete modelling of the product, the process and the resources.
\end{abstract}

Key words: Feature-based process chain, design features, manufacturing features, resource planning, cost estimation

The original version of this chapter was revised: The copyright line was incorrect. This has been corrected. The Erratum to this chapter is available at DOI: 10.1007/978-0-387-35637-2_11 


\section{INTRODUCTION}

In the past, we typically considered isolated parts of the overall process chain because we were basically concerned with implementing improvements within a certain section or extending single parts of the chain. Yet, the current trend towards taking a comprehensive look at the overall process chain means that, instead of solely ensuring continuity of data to effect process improvement, we now require a uniform, digital representation of all of the systems comprising the process in a single, common data and process model. Whereas, exclusively the relationship between the product specification and the process description used to be relevant for process improvement, step by step, the circle has now come fully around to include the description and integration of the resources utilized, as illustrated in Figure 1.

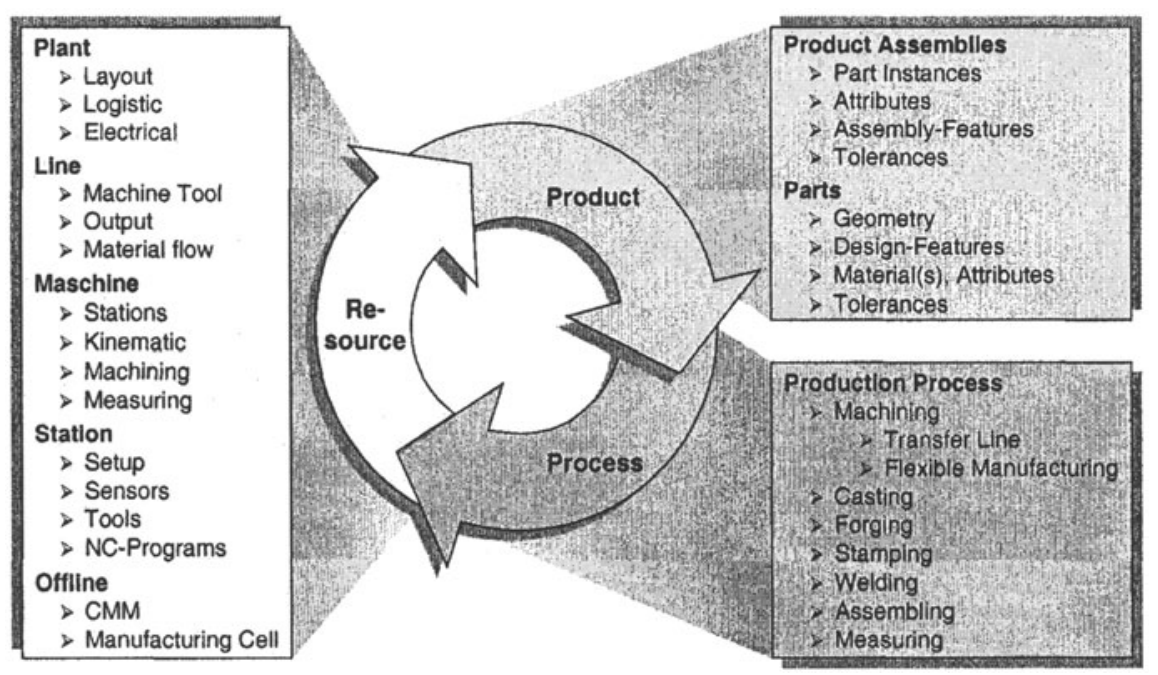

Figure 1. Connection between the product, the process and the resources (Olling 1999)

The use of features as a uniform information medium throughout the process chain is the foundation upon which we base any description of what takes place at any step in the overall process. And the goal of our approach is the complete digitisation of all of the areas concerned in the product creation process (Haasis 1997).

Another reason for taking one step back and looking at the product, the process and the resources as a whole is the corresponding cost estimation. The benefit is that we become capable of making initial cost forecasts at extremely early stages in the process chain by supplementing the entire data network with standard parameters during individual design and $\mathrm{NC}$ planning 
phases, thus enabling early cost optimisation of the individual process phases and ensuring that cost targets are met.

\section{FEATURE-BASED PRODUCT DEVELOPMENT}

The process chain starts with product development. Here, in the first link, the first features are insinuated into the data flow. The availability of design features in the product development phase is the basis for the continuous and comprehensive improvement of the overall product creation process.

What is basically a rudimentary description of the part to be developed is split up into semantically specified partial models, where the geometry of the part is described on the basis of design features, and several design engineers working in concert create the part, e.g. a cylinder head. In a main document, the various partial models are linked together to form an overall model of the complete part. The overall model may be updated after various modifications have been made to the partial models. One of the partial models contains all of the machinable design features. The other partial models combine to describe the form of the unmachined part (Haasis 1999).

Design Features. This group of features contains general feature types such as a blind thread or a through bore, on the one hand, and productspecific feature types like spark plug boreholes for gasoline engines or glow plug boreholes for diesel engines on the other. And design engineers are supported through a kind of intuitive product modelling geared for their specific work-related activities (Haasis 1997). In particular, the functional perspective as perceived by the designer is supported. Each design feature may be organized according to its function and, as such, is offered to the designer for integration into the product. This way of thinking where the feature is linked to its function promotes the creativity of the designer. General design features may be accessed by all designers working within an organization and are standardized throughout the concern (Haasis 1996, Haasis 1995).

The types of features cited above are supplemented by features belonging to assembly work, which are not restricted to a specific part. For example, the assembly feature "screwed part" assigns the design features "through bore" to the plates to be joined through the screwed connection and the standard parts required for this work such as the hexagonal screw, the locking ring and the hexagonal nut. In addition, these features support subsequent assembly planning and logistics operations.

A feature editor was developed for CATIA V5: the software module integrated in the $\mathrm{CAD}$ system supports the designer in functional and 
intuitive product modelling by specifying and storing the feature on the basis of the function to be mapped. Figure 2 shows how the dimensioned blind thread is mapped to the function "positioning".

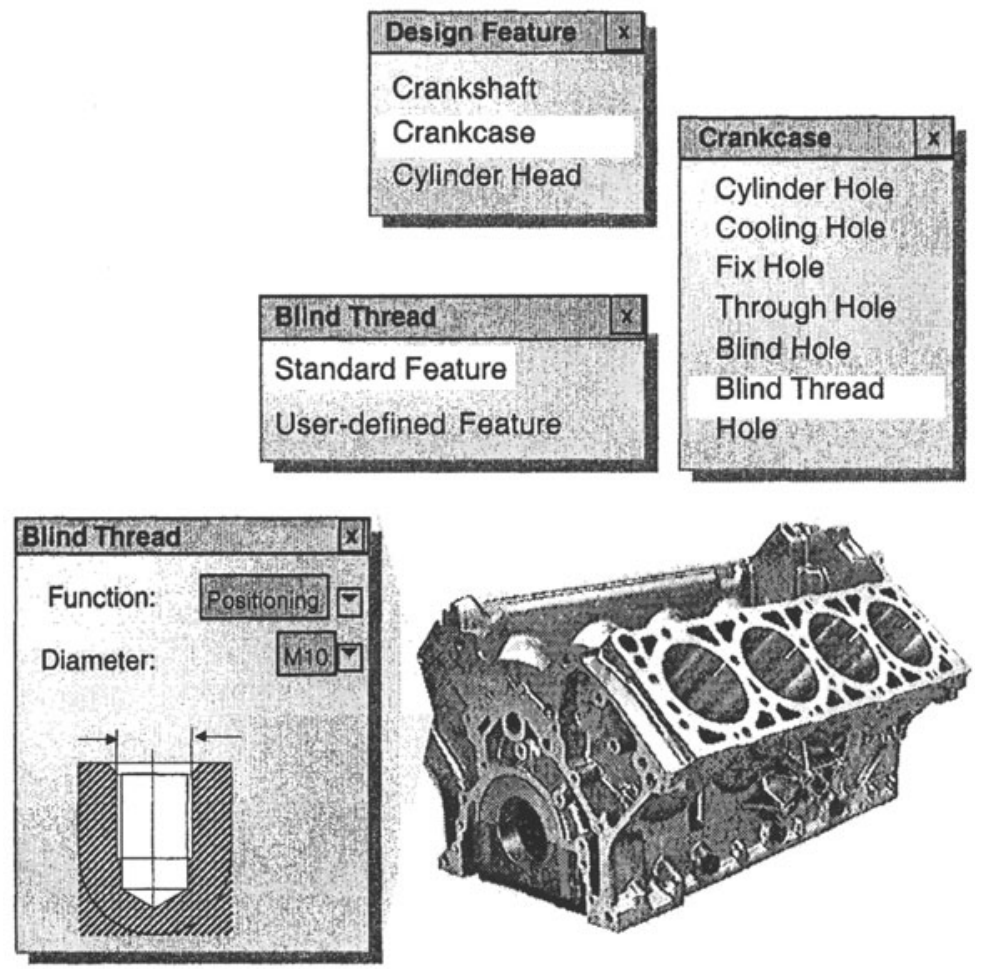

Figure 2. Feature-based product design

The provision of such feature libraries and their deployment considerably accelerate the overall design process. Also, use of standard features ensures efficient product modelling and contributes to enhanced product quality. Designers are provided with tried and tested combinations of parameters which are aligned with the corresponding manufacturing context. Moreover, design engineers are provided with additional user-defined, non-standardized features which they may utilize as needed for their specific design task (Haasis 1997).

While fine-tuning the product model, designers have access to a featurebased cost information system. The result of the analytical approach on the base of a generative process plan is a detailed and differentiated cost estimation that enables us to draw specific conclusions about the cost driver and the possibilities to adjust product cost. Using the product model the generative process plan is derived. It names the machining operations and 
for each operation the necessary resources and the machining time. The cost model evaluates monetarily the machining time using the corresponding hourly rates. Generating the process plan in (Kiritsis 2000) and (OuYang 1997) a rule-based system is used to assign machining operations and resources to features. However, manufacturing technology and the resources available underlie a continuous improvement and change and, machining strategy is often company specific. The methodology of case-based reasoning (CBR) makes it possible to adapt to new manufacturing technology and to consider experience knowledge. (Paulokat 1994) describe the planning for machining workpieces using CBR and (Rehman 1998) use CBR in the field of cost estimation.

The example shown in Figure 3 illustrates how the designer is assisted in evaluating the costs which the digital product model would incur, effecting early cost calculations and meeting targeted costs. Hence, features are vital for ensuring a design process geared for manufacturing and cost efficiency.

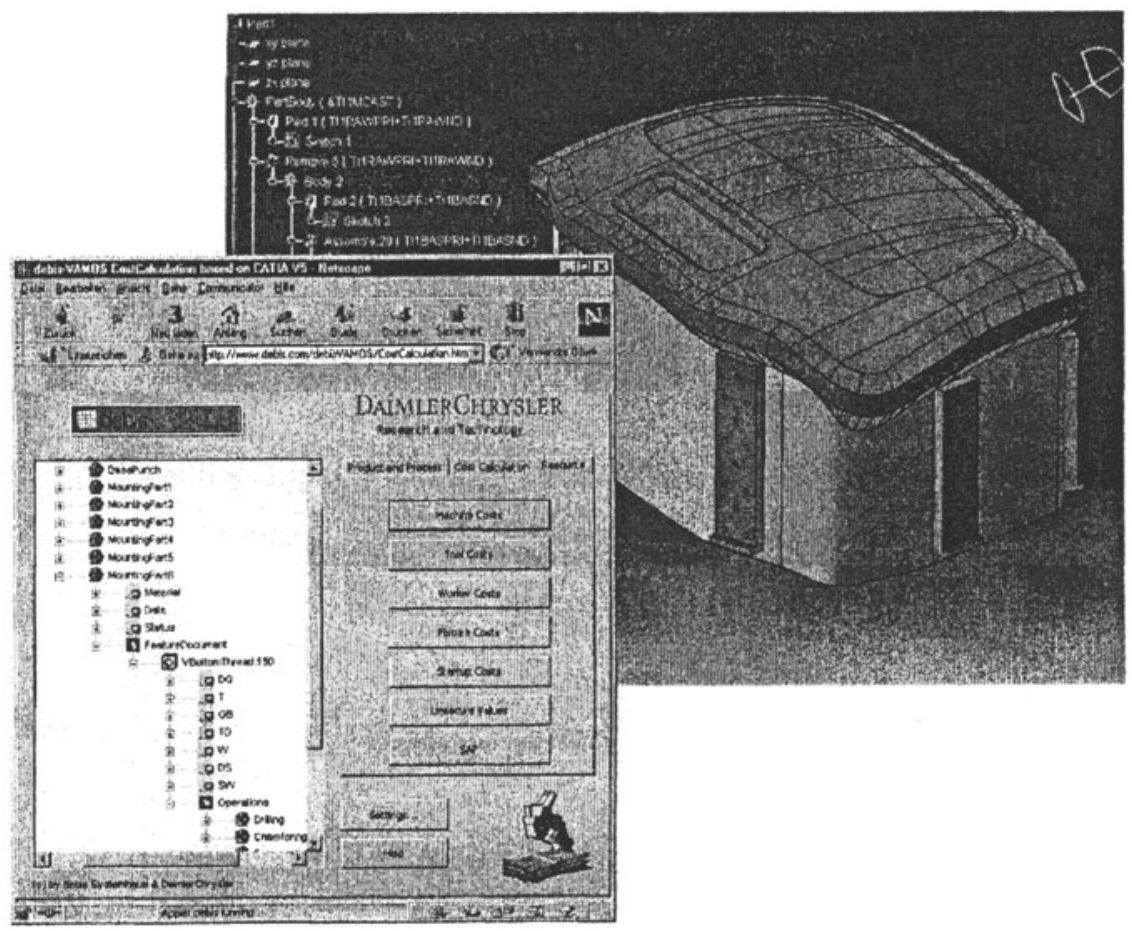

Figure 3. Feature-based cost estimation

Now that the product model has been completed, a model of the related manufacturing process is required. Depending on the maturity of the product 
model and supported by a workflow management system, the work scheduler generates a process plan based on the features used in the product design (Weyrich 1999). The exact role played by features within this subprocess is set out in the following section.

\section{FEATURE-BASED PROCESS DESIGN}

This part of the process chain comprises the modelling of the product manufacturing and inspection on the basis of the features used during product design. We will refer to the applications following the design phase as downstream applications. The CAD model consisting of design feature instances is transformed into several downstream-application-specific feature models. If a design change should be made, the downstream applications are given exact information on any features which have been modified, deleted or added; thus features support change management.

\subsection{The manufacturing perspective}

To create manufacturing models automatically from the design models a process called feature mapping is used. Figure 4 shows as an example design models for the part and its casting tool.

The design models are mapped onto feature-based manufacturing models and inspection models which constitute the specific experts' view on the product or part respectively. These specialists will create manually those elements which cannot be generated automatically during the feature mapping.

The next planning step adds technology-specific information. For instance, when planning the machining process in more detail, the NC planner assigns to the machining features a sequence of individual machining operations. Each operation is, in turn, assigned to exactly one tool that will be used for its execution (Storr 1996, Geissler 1996, Schuetzer 1995).

The system will suggest the operations and tools to be used for the individual machining features. The NC planner reviews these solutions and, if need be, may alter them. 

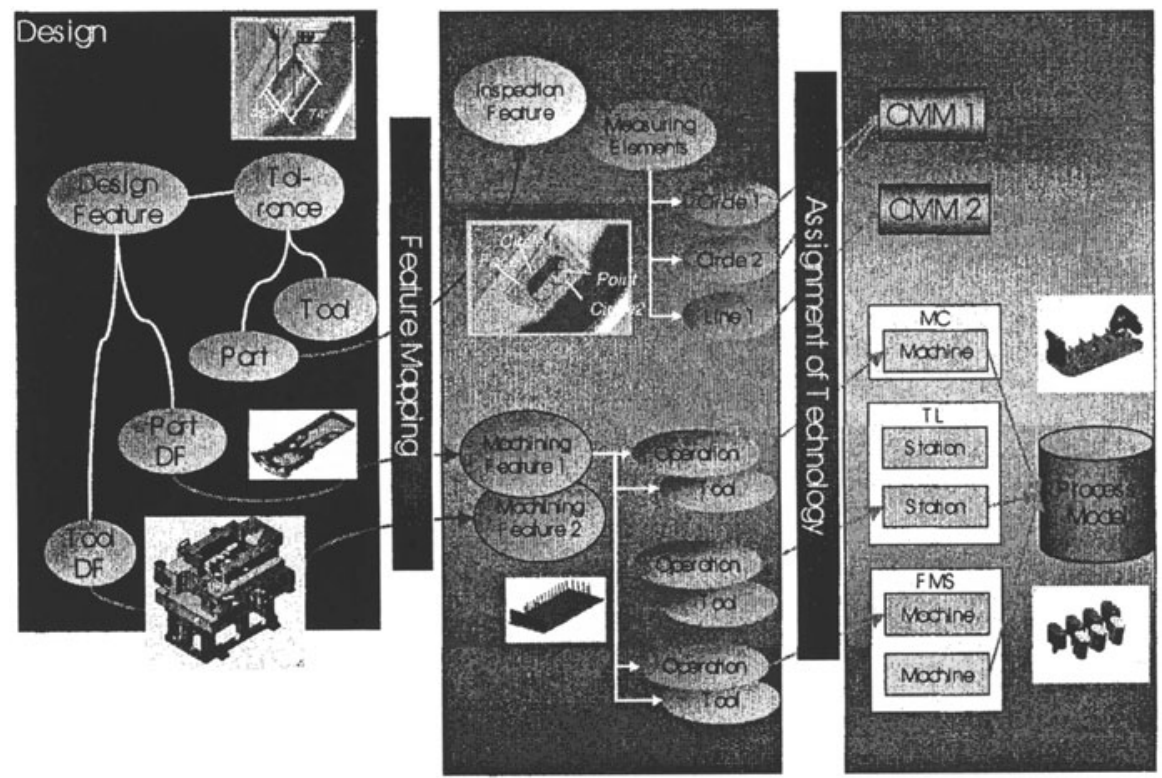

Figure 4. From design to manufacturing (machining, casting) and inspection

\subsection{The process perspective}

The workpiece- or manufacturing feature-oriented structure of the machining model does not contain a suitable sequence of operations for the subsequent manufacturing process. So, a process perspective of the overall machining model has to be generated in parallel to the manufacturing perspective. And, in contrast to the manufacturing perspective, the process perspective consists of a cross-feature sequence of individual operations, each of which is allocated a specific workstation within the manufacturing process.

The scope of operations is distributed to fixtures where several operations according to the requirements which the machining of the workpiece places on the manufacturing process are carried out. Each of these fixtures may incorporate more than one NC program. The operations are divided up between the NC programs to ensure that the machining technologies run in the appropriate order. Before an NC machining program can be generated for such an NC program, a suitable NC machine or workstation has to be specified. Thus, an unbroken link between the design features, the manufacturing features and, finally, the machine to be used for the operations performed in connection with a machining feature is formed. This 
continuous chain of data is the bottom line when determining machining costs during the planning phase. The approaches mentioned above have been implemented in CATIA version 5. Figure 5 shows the CATIA V5 Manufacturing GUI.

Figure 5. Feature-based process planning

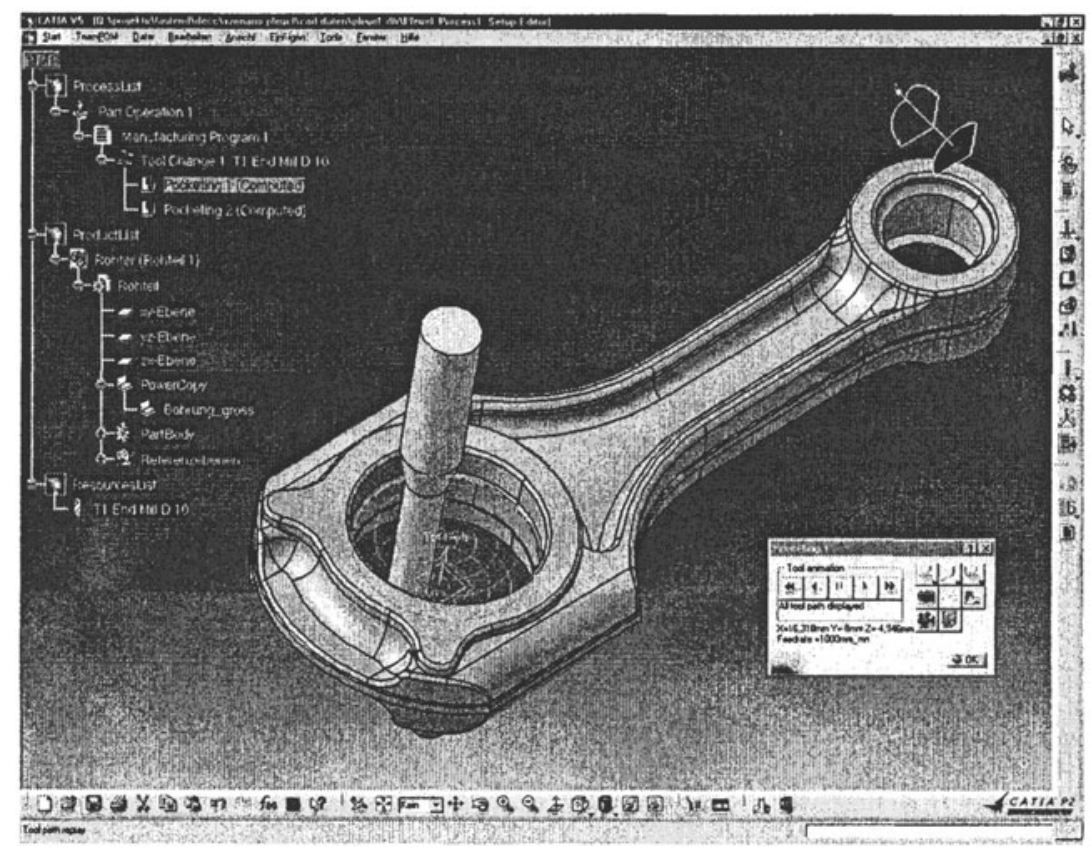

\subsection{The same procedure for measuring operations}

Similar to the procedure described for the machining model is that used for measuring operations. However, naturally, measuring features are generated for the relevant shape elements. And the measuring features are assigned one measuring method and one measuring sensor each during planning of measuring operations. Just as in machining, the workpieceoriented perspective is separated from the process perspective. Where machining techniques and tools are assigned to the machine centres and workstations making up a transfer line, the measuring methods and sensors are assigned to the coordinate measuring devices and measuring stations selected in the line. When the product and process descriptions have been completed, resource planning is effected on the basis of the equipment and facilities required for the manufacturing process. 


\section{FEATURE-BASED RESOURCE PLANNING}

When planning the deployment of manufacturing equipment, engineers use both the existing design results in the form of 3-D models and 2-D drawings and context-relevant product requirements to first create the product specifications. As an integral part of the design results, features, in addition to providing the parts making up the form of the component, yield information on casting aspects, tolerances and other technological requirements. Taking these requirements into account, the best suited machining operations and tools are selected and the resulting machining volume decided. This, in turn, impacts the layout of the stations, machines and lines. Cycle and machining times are considered and the material flow and line layout planned, Figure 6 Here, close cooperation with suppliers and system partners is required, necessitating their integration into this process.

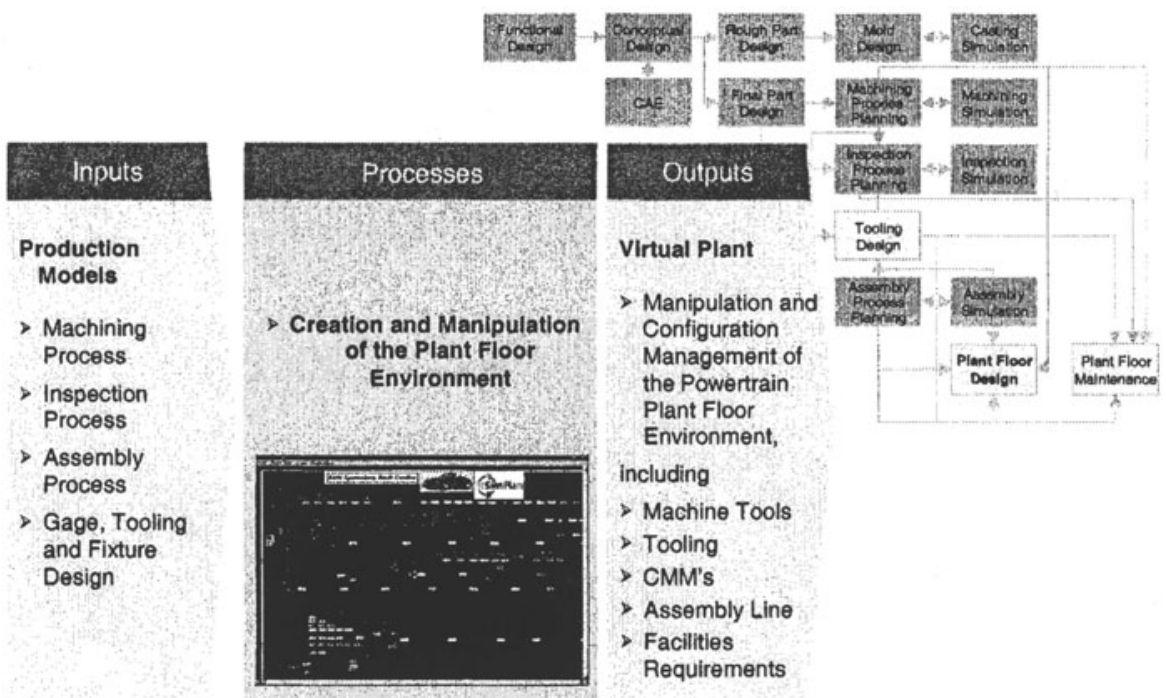

Figure 6. How manufacturing facilities are planned

As soon as the sections of the manufacturing line have been planned by assigning the operations and tools needed and the resulting machining volumes to the stations and machines in the line, a feature-based manufacturing process model may be generated for each resource with the objective of providing a representation of the respective status of the workpiece being machined. This is generated, if required, through subtraction of the 3-D geometry model - unmachined part or status after machining at the previous station - from the sum of the remaining machining volumes at the station. In addition to enabling navigation of the digital 
manufacturing of the part based on the visualized representations of the machining status before and after it has run through a station, these models permit situation-related offline programming of coordinate measuring devices (Haasis 1999). See Figure 7.

Figure 7. Planning manufacturing stages by using 3-D manufacturing process models

Suitable techniques still remain to be developed to facilitate integration

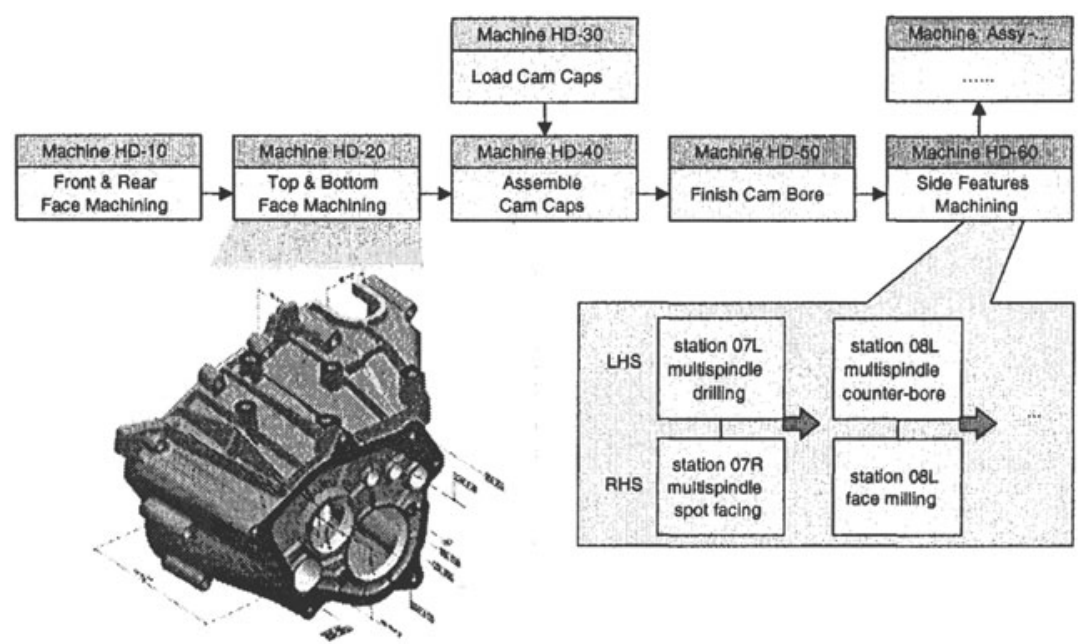

of the approaches described in existing process chains. The chapter set out below shows how the approaches might be implemented in real process chains and describes current project work in this field.

\section{IMPLEMENTATION IN REAL PROCESS CHAINS}

\subsection{Objectives for the realization of the data model}

The integration of process chains is an essential task if changes to processes are to be made quickly and with optimal resources. In order that single links in the process chain may be more easily integrated, a new generation of IT tools is required to enable effective data exchange. In this connection, a performing change management throughout those systems of the process chain concerned is a necessity for the practical implementation. Hence, a uniform data model to be deployed throughout the process chain 
for quick and easy data exchange between the individual processes has become a top priority.

Features offer a performing methodology for the encapsulation of information and its exchange as a logical unit at the process seams. And continuity of the process chain in the case described in the previous chapters is given through the linking of data from design, process planning, prototype construction and mass production. Of course, features need to be structured appropriately to ensure that they are suitable carriers of the information generated in the different processes. Hence, the challenge we face is how to design and implement structured features as building blocks for the transfer of data throughout the process chain to enhance continuity and control in the long run (Haasis 1996).

\subsection{Process chains}

Today's process chains are characterized by a strict demarcation between sub-processes, which represents a barrier to the flow of information. The borders between the individual processes are historical in origin and their continued growth is typically a result of the organizational structure of the concern (Haasis 1996).

In the conventional process chain as frequently implemented throughout industry today, there are two barriers to the data flow, i.e. there are three separate and distinct process areas. As a rule, the first area is design, where $\mathrm{CAD}$ tools play the major role in the generation of data. Design is clearly separated from the second area, prototyping, and its related data generation from NC programming. In prototyping, small lots are produced at machining centres programmed using special CAM tools. After NC machining and prototyping have been successfully completed, mass production of the product - the third area mentioned - can begin. In mass production, transfer lines are set up for the manufacturing of very large lots in contrast to the machining centres used in small-lot prototype manufacture. This represents the second block to the data flow, as mass production is controlled by entirely different machine programs customized for transfer lines. Unfortunately, in practice, design changes often need to be made after commencement of mass production, thus necessitating corresponding changes in all the areas concerned from the beginning of the process chain to the end at the machine. The result is a drastic increase in the time and effort required.

In flexible manufacturing - supported through feature technology - the barriers between the process parts are torn down. However, this can only be done if the digital transfer of data is warranted from the beginning of the process chain - design - through prototyping and on to the manufacturing 
process itself. In principle, standard formats (e.g. STEP) would seem a suitable way of effecting the exchange of data. However, practice has shown that single-vendor CAx system solutions where system modules are implemented in the process areas involved are the better alternative since they enable efficient data exchange within a single system environment.

Implemented on top of a CAD/CAM platform in place within a process chain, feature technology would form an excellent basis for the compilation of information and its transfer in the form of a logical unit over the border from design to NC programming. Although the form in which the features are represented would, of course, have to change due to the very different perspectives inherent in design and manufacturing, a great deal of data content could be transferred as is, without change.

The second barrier to data flow is the exchange of NC programs between the machines used in prototyping and those deployed in mass production. With ISO 14649, new machine programming standards are in the pipeline for the improved data exchange between machines of different types. Here also, feature technology would provide a suitable means of facilitating data transfer by enabling the creation of NC programs which are independent of the type of machine and the control system deployed.

\subsection{Implementation}

The process chain as set out in the previous sections will be migrated to a chain supported by features. To solve the underlying problem of data continuity, DaimlerChrysler has entered into a strategic partnership with the French-based systems house Dassault, establishing the CAx system CATIA as the system of choice organization wide. In spite of the restriction this puts on the possible options open for system deployment, continuous data exchange from the beginning to the end of the process chain is ensured due to this single-system solution. Also, this framework has enabled activities pertaining to continuous feature processing to be carried out, with the concrete goal of establishing a feature library tailor-made for the CAD and CAM applications deployed within the organization.

The Process Development Department in Untertuerkheim bore the overall responsibility for integrating the system at DaimlerChrysler. The system is based on CATIA V5 and is made up of three major components (Haasis 1997):

- A feature editor as a CAD module for workpiece modelling, including a feature library.

- A CAM module for intuitive NC programming.

- Extended functionalities for flexible manufacturing and simulation. 
The components are currently implemented as prototypes for drilling and milling applications and are deployed in product industrialization. Further modules for NC machining simulation and workpiece fixture planning are in the pipeline.

The prototype as implemented in the process chain has served to evidence the great potential inherent in feature technology: features have proved their suitability for uninterrupted data flow throughout the process chain. At the same time, we have found that the related feature libraries set up need to be carefully structured and tailor-made to the processes in place within the organization or they will not be widely accepted by the users.

\section{CONCLUSION}

Feature technology comprises the deployment of design, manufacturing and measuring features in their respective areas and serves as a backbone for the bi-directional flow of information throughout the overall process chain, thus enabling continuous, digital product and production modelling (Haasis 1997, Haasis 1999). Should any changes be made in design in a featurebased process chain, the resulting impact on the costs incurred, the machining technologies to be adapted, including utilization capacities, and the quality of the product are quickly and easily derived. The provision of standard features in application-specific feature libraries allows standardization and ensures the desired quality of the product description. In addition, direct access to these standard libraries accelerates the design process and permits initial cost estimations as early in the overall process as the design stage. When standard features are brought into alignment with manufacturing, the stocks of tools required for production can be right sized, leading to further cost cutting. In NC programming, the machining techniques used are closely coupled to the manufacturing features, thus enabling the creation of a feature-based object-oriented NC program, which, through the development of a new generation of $\mathrm{NC}$ controls, may be directly read and edited in the future (Haasis 1993). The distribution of machining techniques to the $\mathrm{NC}$ machines as needed will enhance the utilization capacity. And, similar to the creation of $\mathrm{NC}$ programs where machining techniques and tools are assigned to manufacturing features, feature technology supports measuring programming (Haasis 1994) by assigning measuring techniques and tools to measuring features. See Figure 8. 


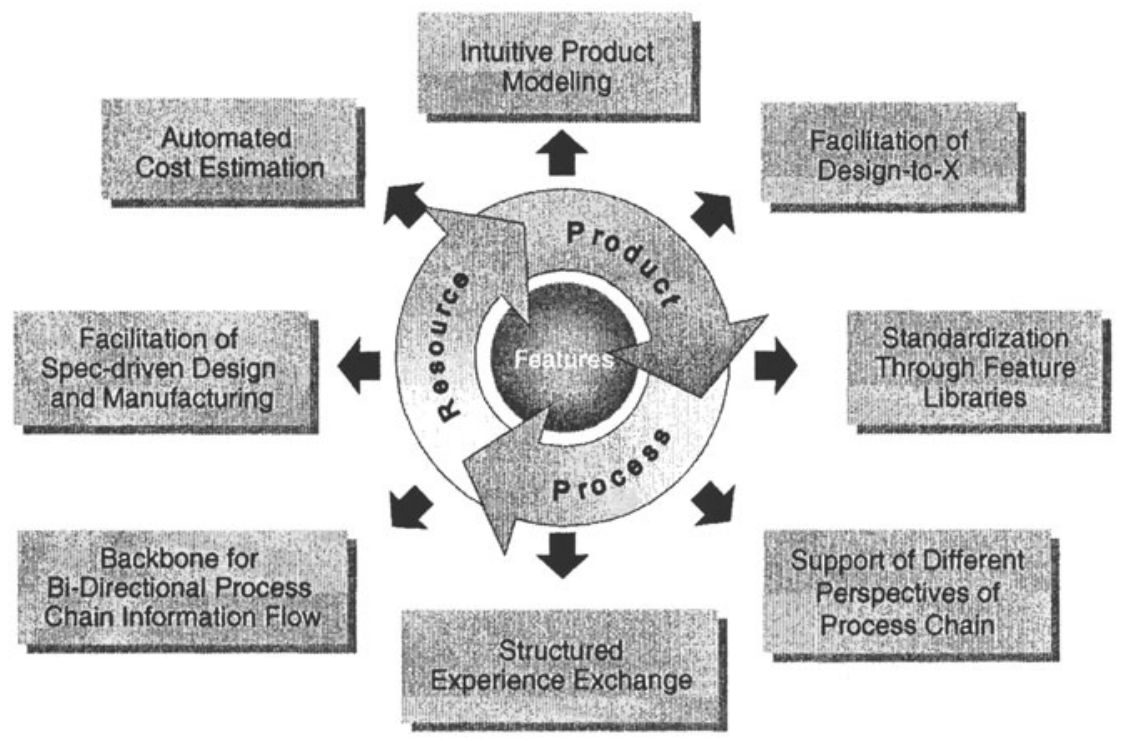

Figure 8. Benefits expected through the deployment of feature technology

Initial integration tests have evidenced the potential inherent in feature technology (Haasis 1997):

- Feature technology accelerates generation of product and manufacturing descriptions.

- Feature technology leads to the efficient creation of NC programs, their optimisation and to efficient change management.

- Feature technology enables integration of CAD/CAM data by means of integrated data administration in CATIA V5.

Yet, the full potential of feature technology can only be exploited if feature-based workflows are implemented throughout the process chain. Partial utilization of features in parts of the process chain results solely in partial benefit. Only through the continued, consistent transfer of feature technology to the workflows in the process chains deployed within the DaimlerChrysler AG business units will the maximum yield be reaped.

\section{REFERENCES}

Gao, J. X., Huang, X. X. (1996). Product and Manufacturing Capability Modelling in an Integrated CAD/Process Planning Environment, Int. Journal of Advanced Manufacturing Technology 11, No. 1, pp. 43-51. 
Geissler, K., Wilfert, H. G. (1996). Generative Arbeitsplanung in der Fertigungsindustrie, ZwF 91, No. 3, pp. 105-108.

Haasis, S. (1997). Feature-basierte Prozesskette mit Object-NC. In Technologietage 1997 der Daimler-Benz $A G$.

Haasis, S. (1998). Feature-Based Process Chain within the Scope of Powertrain Engineering. Proceedings of the 31st ISATA, 2nd - 5th June 1998, Duesseldorf, pp 113-120.

Haasis, S. (1997). Handlungsorientierte Gestaltung von CAx-Systemen entlang der Prozesskette. In $K I K$ '97. Konstanz: Universitaetsverlag,.

Haasis, S. (1997). Nutzenpotentiale der durchgaengigen Feature-Verarbeitung, VDIBerichte Nr. 1322, VDI-Verlag, Duesseldorf, pp. 63-82.

Haasis, S., Bär, T.; Pfeifle, J.; Rothenburger, G.; Schulze, H.; Ströhle, H.: User-Oriented Inspection Model for Powertrain Engineering. Science Days 2000, Sindelfingen.

Haasis, S., Katzenbach, A.: Engineering Processes of the Future. Digital Products Living Data is the Future. Page 65-73. Teubner, Stuttgart: 2000.

Haasis, S., Rose, H., Schulze, H. (1999). Technische Unterstuetzung erfahrungsgeleiteter Arbeit mit Prozessketten in der Produktion, In Innovation und Kooperation Nutzerorientiertes Konzept fuer Interaktionssysteme in der Serienfertigung., Campus Verlag, Frankfurt u. New York.

Haasis, S.; Schulze, H. (1997). Erfahrungsgeleitete Arbeit mit Prozessketten in der Produktion, 1. Kassler Kolloquium.

Kiritsis, D., Xirouchakis, P. (2000). DEVIPLAN: A bid preparation system for mechanical SME, In Proceedings of DETC2000.

Meier, M., Bichsel, M., Elspass, W., Leonhadt, U., Wohlgesinger, M. \& Zwicker, E. (1999). Neuartige Tools zur effizienten Nutzung der Produktdaten im gesamten Produktlebenszyklus. Konstruktion (9), 11-18.

Olling, G.; Nedwick, J; Scharpf, J. (1999). Common View of CAD/CAM Technology Integration in Powertrain Processes. DaimlerChrysler: Stuttgart and Auburn Hills.

Ou-Yang C., Lin, T.S. (1997) Developing an integrated framework for feature-based early manufacturing cost estimation, Advanced Manufacturing Technology, pp. 618-627.

Paulokat, J., Wess, S. (1994). Planning for machining workpieces with a partial-order, nonlinear planner, In: Proceedings of: AAAI Fall Symposium "Planning and Learning: On to Real Applications".

Rehman, S., Guenov, M.D. (1998). A methodology for modelling manufacturing costs, Computers and Industrial Engineering, Vol. 35, No. 3-4, pp. 623-626.

Salomons, O. W. D., Geelink, R., Van Slooten, F., Van Houten, F. J. A. M. ,. P. \& Kals, H. J. J. ,. P. (1998). Definition of design and manufacturing form features [TwenteLiteratur]. In Proceedings of 31st CIRP International Seminar on Manufacturing Systems; Networked Manufacturing: Integrated Design, Prototyping and Rapid Fabrication, May 26-28, 1998, Berkley, California .

Shah, J. J. \& Mäntylä, M. (1995). Parametric and feature-based CAD/CAM. Concepts, Techniques, and Applications. New York: John Wiley \& Sons.

Shah, J. J. \& Yan, Y. (1996). Representation and Mapping of Geometric Dimensions from Design to Manufacturing. In Proceedings of the 1996 ASME Design Engineering Technical Conferences and Computers in Engineering Conference, August 18-22, 1996, Irvine, California (S. 1-11).

Shah, J. J., Bhatnagar, A. \& Hsiao, D. (1988). Feature Mapping and Application Shell. In Proceedings of ASME Computers in Engineering Conference (S. 489-498). 
Shah, J. J., Yan, Y. \& Zhang, B-C. (1998). Dimension and tolerance modeling and transformations in feature based design and manufacturing. Journal of Intelligent Manufacturing, 9 (5), 475-488.

Storr, A., Rommel, B. (1996). Bearbeitungsobjekte als Basis fuer Informationsmodelle. In Objektorientierte Produktionsarbeit: neue Konzepte fuer die Fertigung. Campus Verlag, Frankfurt u. New York.

Van Diepen, A. (1993). CAD-CAPP integration for sheet metal products [Master of Science Thesis]. Twente (NL): University Twente.

Weyrich, M. (1999). Multimediale Werkzeuge zur 3D-Planung im Maschinen- und Anlagenbau. VDI-Verlag, Duesseldorf.

Weyrich, M.; Rommel, B.; Haasis, S.; Müller, P.: First Prototype of a NC Controller Based on STEP-NC. Science Days 2000, Sindelfingen.

Wolfram, M.(1994). Feature-basiertes Konstruieren und Kalkulieren, Hanser, Muenchen u. Wien. 